\title{
Covalent immobilization of the Jacobsen catalyst on mesoporous phenolic polymer: a highly enantioselective and stable asymmetric epoxidation catalyst
}

Jeroen De Decker ${ }^{[a]}$, Thomas Bogaerts ${ }^{[a, b]}$, Ilke Muylaert ${ }^{[a]}$, Sander Delahaye ${ }^{[c]}$, Frederic Lynen ${ }^{[c]}$, Veronique Van Speybroeck $^{[\mathrm{b}]}$, An Verberckmoes ${ }^{[\mathrm{d}]}$, Pascal Van Der Voort ${ }^{[\mathrm{a}, *]}$

[a] Department of Inorganic and Physical Chemistry, Center for Ordered Materials, Organometallics and Catalysis (COMOC), Ghent University, Krijgslaan 281-S3, 9000 Ghent, Belgium.

${ }^{[\mathrm{b}]}$ Center for Molecular Modeling, Ghent University, Technologiepark 903, 9052 Zwijnaarde, Belgium.

${ }^{[c]}$ Department of Organic Chemistry, Separation Sciences, Ghent University, Krijgslaan 281-S4, 9000 Ghent, Belgium.

[d] Associated Faculty of Applied Engineering Sciences, University College Ghent, Valentin Vaerwyckweg 1, 9000 Ghent, Belgium.

*Corresponding author: P. Van Der Voort, Department of Inorganic and Physical Chemistry, Center for Ordered Materials, Organometallics and Catalysis (COMOC), Ghent University, Krijgslaan 281-S3, 9000 Ghent, Belgium. Tel.: +329242 42 44. E-mail: pascal.vandervoort@ugent.be

\begin{abstract}
The Jacobsen catalyst, N,N'-bis(3,5-di-tert-butylsalicylidene)-1,2-cyclohexanediaminomanganese (III) chloride is covalently immobilized on mesoporous phenolic resin through a direct and simple procedure. The immobilization is evident from nitrogen sorption and quantitative XRF measurements. A complex loading of $0.09 \mathrm{mmol} / \mathrm{g}$ is obtained, corresponding to well dispersed Mn-complexes on the surface of the mesoporous phenolic resin. This novel catalytic system shows good catalytic activity and excellent enantioselectivity in the asymmetric epoxidation of 1,2-dialin. The heterogenized Jacobsen catalyst is demonstrated to be a re-usable and non-leaching catalytic system.
\end{abstract}

Keywords: polymers, microporous materials, chemical synthesis, Fourier Transform Infrared Spectroscopy (FTIR), chemisorption, oxidation 


\section{Introduction}

Epoxides are versatile intermediates in organic chemistry. Their inherent polarity and the strain in the threemembered ring makes them interesting compounds for regioselective ring opening reactions, followed by the formation of 1,2-difunctional products ${ }^{[1-3]}$. In particular, optically pure epoxides with two vicinal chiral centers are often used as intermediate in the synthesis of biologically and pharmaceutically active compounds ${ }^{[4]}$. Today, the synthesis of chiral epoxides generally occurs by oxidation of olefins. In this field, the asymmetric epoxidation of unsubstituted alkenes is not facile since no substituents are present to control the orientation of the substrate. The Jacobsen catalyst, a manganese (III) salen complex, has proven to be a very efficient catalyst for asymmetric alkene epoxidation reactions ${ }^{[5]}$. As shown in Figure 1 (Left), these salen type complexes have two chiral $\mathrm{sp}^{3}$ hybridized carbon atoms $(*)$ in the vicinity of the metal center. The presence of these two stereogenic centers enables excellent stereochemical control in the epoxidation step. Furthermore, these complexes possess bulky $t$-butyl groups on the aromatic rings, acting as substrate directing agents (Fig. 1). The Jacobsen catalyst can react with a variety of terminal oxidants, such as hydrogen peroxide, sodium hypochlorite and iodosyl arenes, forming activated oxo-manganese (V) species that are able to epoxidize contacting alkene substrates $^{[6]}$.

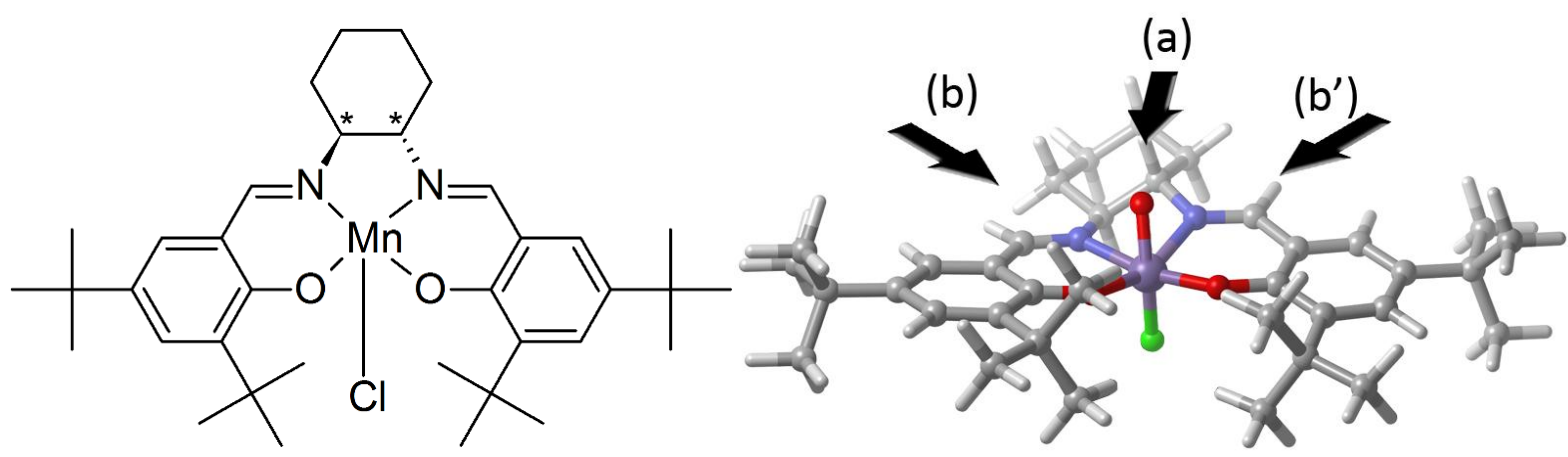

Figure 1 - (Left) Structure of the Jacobsen catalyst, N,N'-bis(3,5-di-tert-butylsalicylidene)-1,2cyclohexanediaminomanganese (III) chloride. The chiral carbon atoms are denoted with an asterisk. (Right) Spatial structure of the activated Jacobsen catalyst. The arrows indicate the possible approaches of the olefin substrates to the active site of the catalyst.

Figure 1 (Right) shows the activated Jacobsen catalyst. Due to sterical hindrance of the bulky $t$-butyl groups, the olefin substrates are forced to approach the activated manganese center via the dissymmetric diimine bridge (pathways $a, b$ and $\left.b^{\prime}\right)^{[7,8]}$.

The major drawback of these catalysts, however, is the deactivation process in homogeneous phase due to the formation of inactive dimeric $\mu$-oxo manganese (IV) species $^{[9-11]}$. In recent years, heterogenization through immobilization of these homogeneous salen-type catalysts on mesoporous supports has become an object of intensive research. Due to local site isolation of the complexes on a solid matrix, dimerisation can be prevented. Furthermore, the possibility of simple recyclability after the catalytic run makes these expensive complexes more economically attractive. The majority of the reports on the heterogenization of Mn (III) salen catalysts have mostly been centered on encapsulation, adsorption or covalent attachment to porous inorganic supports, such as 
zeolites, MCM-41, Al-MCM-41, mesoporous silicagel, SBA-15 and clays ${ }^{[1,12-19]}$. These strategies have proven to be efficient, yet for covalent immobilization the original structure of the manganese complex is modified or multiple synthetic steps and structural changes to the parent catalyst structure and support are required. Intensive research on the heterogenization of salen-type and other metal complexes has been performed by De Vos et al., being particularly successful in the field of zeolite encapsulation and silica grafting ${ }^{[20-22]}$. Various metallosalen complexes and analogues have been anchored successfully on hybrid porous materials such as ordered mesoporous organosilicas (PMOs) and metal organic frameworks (MOFs) ${ }^{[23]}$. Various attempts to produce polymer-supported Jacobsen catalysts have been reported, e.g. through attachment via the aromatic rings, by binding pre-formed $\mathrm{Mn}$ complexes to a pyridine-containing polystyrene-based resin or by physical entrapment of the complex within a suitable polymer matrix ${ }^{[24-28]}$. Silva et al. published the immobilization of the Jacobsen catalyst through a direct axial coordination of the metal center onto the phenolate groups of a modified, commercial, activated carbon ${ }^{[29]}$. This immobilization procedure involves a direct and simple reflux procedure. The newly developed catalysts showed high activity in the asymmetric epoxidation of styrene and $\alpha$ methylstyrene, using PhIO and $m$-CPBA as oxidants. However, the obtained $e e$ values were rather moderate ${ }^{[30]}$. Also, prior to the immobilization of the manganese complex on activated carbon, the carbon surface has to be pre-treated by an oxidation step (mostly by $\mathrm{H}_{2} \mathrm{O}_{2}$ treatment or with an air flow) in order to generate sufficient surface phenolic hydroxyl functions as anchoring points ${ }^{[29]}$. When the procedure was applied on carbon xerogels, the surface pretreatment was performed under $5 \% \mathrm{O}_{2}{ }^{[31]}$.

In this study, mesoporous phenolic resins are introduced as a novel support for the manganese (III) salen complex. These phenolic resins are an advanced class of mesoporous materials combining a high porosity with the organic properties of the corresponding polymer. Moreover, this new generation of mesoporous materials has shown to be highly stable, both thermally and mechanically ${ }^{[32,33]}$. The mesoporous phenolic resins contain an abundance of phenolic hydroxyl groups in their framework. Consequently, the pre-oxidation is not required for these materials, providing a time efficient synthesis pathway. This newly developed catalyst is evaluated for its catalytic performance in the asymmetric epoxidation of dialin (1,2-dihydronaphthalene). The results are compared to the catalytic activity of the homogeneous Jacobsen catalyst system. To evaluate the recyclability and the resistance to leaching, the heterogeneous catalyst was used in three consecutive epoxidation reactions.

\section{Experimental}

\subsection{Chemicals}

Resorcinol, Formalin (36\%), Pluronic F127, Jacobsen catalyst (N,N'-bis(3,5-di-tert-butylsalicylidene)-1,2cyclohexanediaminomanganese (III) chloride), 1,2-dihydronaphthalene and sodium hypochlorite solution (10\%) were purchased from Sigma Aldrich. Suprapur Nitric acid 65\% was purchased from Merck Chemicals. All chemicals were used as received.

2.2 Synthesis of mesoporous phenolic resin 
In a typical synthesis, resorcinol (2.2 g) and Pluronic F127 (2.2 g) were dissolved in ethanol (9.0 mL) containing $\mathrm{HNO}_{3}(3 \mathrm{M}, 9 \mathrm{~mL}$ ) during $15 \mathrm{~min}$ at room temperature. Subsequently, $2.6 \mathrm{~g}$ of aqueous formaldehyde solution (36 wt \%) was added dropwise to the above solution, under continuous stirring. After an additional 15 min of stirring, the resulting clear solution was poured and dried on a dish during $6 \mathrm{~h}$ to evaporate the ethanol. The sample was then collected and cured at $333 \mathrm{~K}$ for $11 \mathrm{~h}$, resulting in a yellow-red colored resin. The template block copolymer was removed through calcination at $673 \mathrm{~K}$ for $6 \mathrm{~h}$ (heating rate: $1^{\circ} \mathrm{C} / \mathrm{min}$ ), resulting in black colored resin.

\subsection{Asymmetric epoxidation of dialin (1,2-dihydronaphthalene)}

The performance of the novel heterogeneous catalyst was evaluated in the asymmetric epoxidation of 1,2-dialin, using sodium hypochlorite $(\mathrm{NaOCl})$ as oxidant. In a typical reaction, $0.05 \mathrm{~g}$ of heterogeneous catalyst $(0.09$ $\mathrm{mmol} \mathrm{Mn} / \mathrm{g})$ was added to a solution of dialin $(0.077 \mathrm{mmol}), \mathrm{NaOCl}(0.077 \mathrm{mmol})$ and dichloromethane $(5 \mathrm{~mL}$, solvent). After stirring for $24 \mathrm{~h}$ at room temperature, the catalyst was filtrated from the reaction mixture and the conversion and enantiomeric excess were determined by HPLC, using toluene as internal standard. The formation of the epoxide is confirmed by ${ }^{1} \mathrm{HNMR}$. The heterogeneous catalyst was recovered and tested in a second and third run at the same conditions. The amount of homogeneous Jacobsen catalyst tested was $0.0113 \mathrm{~g}$ $(0.396 \mathrm{mmol} \mathrm{Mn} / \mathrm{g})$ in order to have the same amount of Mn centers as are present in the heterogeneous catalyst ( $0.09 \mathrm{mmol} \mathrm{Mn} / \mathrm{g}$ or $0.0045 \mathrm{mmol} \mathrm{Mn} \mathrm{per} 0.05 \mathrm{~g}$ of tested heterogeneous catalyst).

\subsection{Characterization}

Nitrogen gas sorption experiments were conducted at $77 \mathrm{~K}$ with a Micromeritics Tristar 3000. Samples were vacuum dried at $120^{\circ} \mathrm{C}$ prior to analysis. The pore size distribution was calculated using the BJH method. Total pore volume was determined at $\mathrm{p} / \mathrm{p}^{\circ}=0.97-0.99$. The specific surface area was calculated using the BET method. DRIFT-spectra were measured on a Nicolet 6700 FT-IR spectrometer from ThermoScientific. UV-vis measurements were performed on a Shimadzu Spectrophotometer UV-1800. X-ray fluorescence (XRF) spectroscopy measurements were performed on a Bruker system with molybdenum X-rays. XPS measurements were recorded on an X-ray photoelectron spectroscopy S-Probe XPS spectrometer with monochromated Al $(1486 \mathrm{eV})$ exciting radiation from Surface Science Instruments (VG). A flood gun was used and set to $10 \mathrm{eV}$. A nickel grid was placed $3 \mathrm{~mm}$ above the samples in order to suppress charging of the samples.

Chiral HPLC analyses were performed on a Waters 2690 separation module, equipped with a UV detector (220 $\mathrm{nm})$, using a Daicel AD-H-type column with hexane/isopropanol (98/2 vol.\%) as mobile phase at a flow rate of $0.900 \mathrm{~mL} / \mathrm{min}$.

The reaction products were identified by ${ }^{1} \mathrm{H}$ NMR. 1,2-dihydronaphtalene oxide. ${ }^{1} \mathrm{H}$ NMR $\left(300 \mathrm{MHz}, \mathrm{CDCl}_{3}\right): \mathrm{d}$ 7.4e7.2 (4H, m, Ar), 3.85 [1H, d, J 4.5 Hz, CH(O) $\left.\mathrm{CHCH}_{2}\right], 3.73$ [1H, dd, J 4.3, $\left.3.0 \mathrm{~Hz}, \mathrm{CH}(\mathrm{O}) \mathrm{CHCH}_{2}\right], 2.80$ $(1 \mathrm{H}, \mathrm{m}), 2.55(1 \mathrm{H}, \mathrm{dd}, J 6.0,15.5 \mathrm{~Hz}), 2.43(1 \mathrm{H}, \mathrm{m}), 1.78(1 \mathrm{H}, \mathrm{m})^{[34]}$. 


\section{Results and Discussion}

3.1 Covalent immobilization of Manganese-Salen complex on mesoporous phenolic resin

Figure 2 gives an overview of the synthesis strategy to immobilize the Jacobsen catalyst on the surface of mesoporous phenolic resin. In step (i), the hydroxyl surface was activated by refluxing with an aqueous solution of sodium hydroxide $(0.03 \mathrm{M})$ for one hour. A decrease in $\mathrm{pH}$ of the aqueous solution was observed, indicating the exchange of phenolic protons $(\varphi-\mathrm{OH})$ for sodium cations $(\varphi-\mathrm{ONa})$, which causes partial neutralization of the alkaline solution. The solid was then filtrated and deionized water was used to rinse the polymer, making it $\mathrm{NaOH}$-free. This washing step was repeated until constant $\mathrm{pH}$. Subsequently the material was vacuum dried at $120^{\circ} \mathrm{C}$. In step (ii), $0.5 \mathrm{~g}$ of the activated solid was refluxed for 6 hours together with $0.05 \mathrm{~g}$ of commercial Jacobsen catalyst in $100 \mathrm{~mL}$ of absolute ethanol. Subsequently, in order to remove the excess of physisorbed complexes Soxhlet extraction was performed. Ethanol was used in this extraction, being a good solvent to the Jacobsen complex. After 24 hours of Soxhlet extraction the solid was filtrated and vacuum dried at $120^{\circ} \mathrm{C}$ for 15 hours.

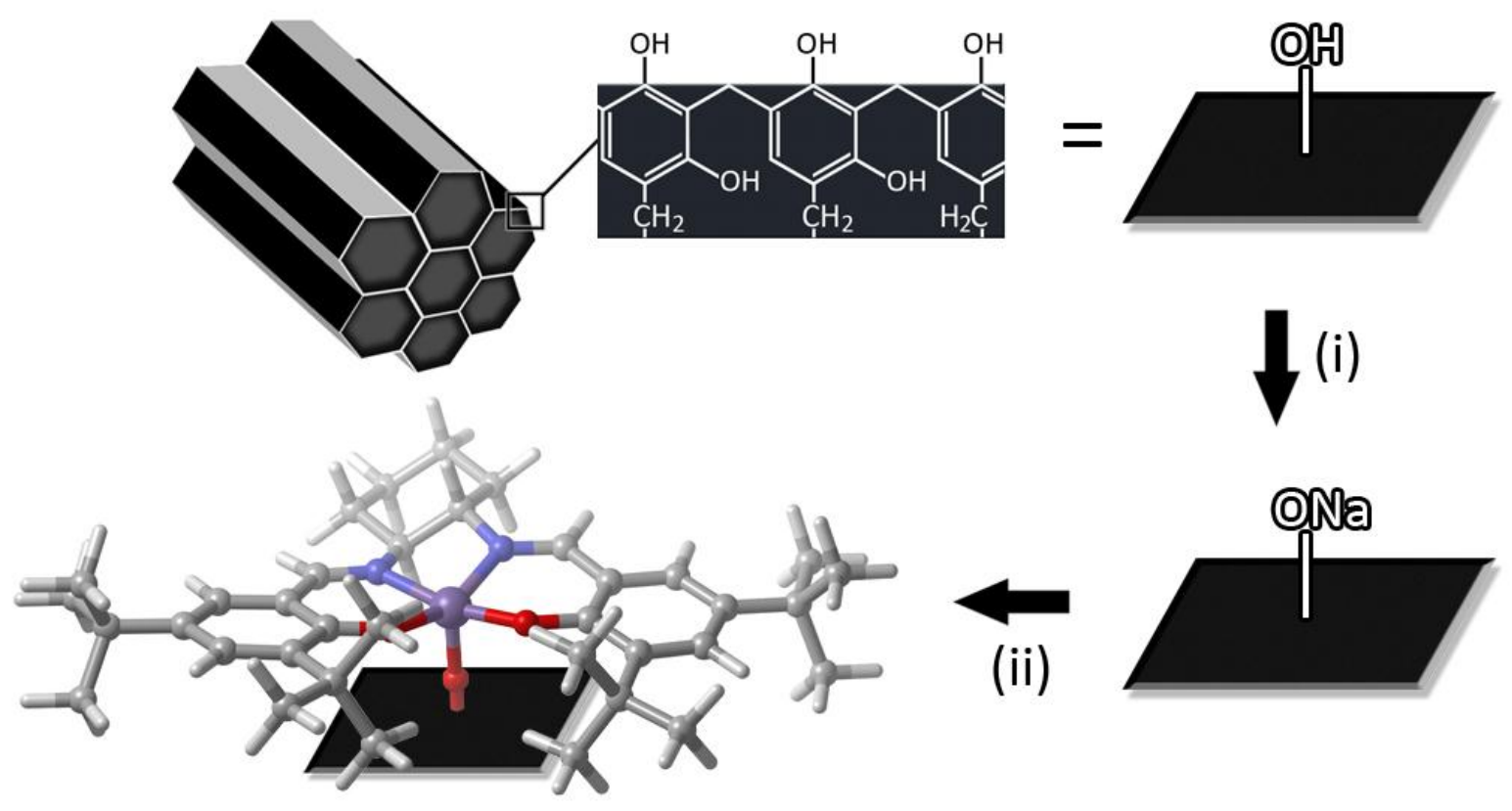

Figure 2 - Covalent immobilization of the Jacobsen catalysts through direct axial coordination on the surface phenol groups of a mesoporous phenolic resin. The resin contains a large abundance of surface phenolic hydroxyl groups. (i) Activation of surface hydroxyl groups by reflux in $\mathrm{NaOH}$ solution. (ii) Anchoring of the salen complex by exchanging the sodium cation with the manganese center of the complex. Color index: Manganese (purple), Nitrogen (blue), Oxygen (red).

\subsection{Characterization}

The immobilization procedure of the Mn-salen complex on the phenolic resin was monitored by means of UVvis spectroscopy of the solution of the homogeneous Jacobsen catalyst $(0.05 \mathrm{~g}$ in $100 \mathrm{~mL}$ absolute ethanol) 
before and after $6 \mathrm{~h}$ reflux with $0.5 \mathrm{~g}$ of the activated phenolic resin. The peak at $492 \mathrm{~nm}$ of the d-d transition of $\mathrm{Mn}(\mathrm{III})$ was reduced with $45 \%$ after 6 hours, indicating a successful loading (of about $0.072 \mathrm{mmol} / \mathrm{g}$ ) of Manganese salen complex onto the phenolic resin ${ }^{[35]}$.

The nitrogen sorption isotherm and the pore size distribution of the immobilized catalyst are shown in Figure 3. The figure shows a type IV isotherm with an $\mathrm{H}_{1}$-type hysteresis loop, indicating the mesoporous structure of the support material. A clear capillary condensation step is observed between $\mathrm{p} / \mathrm{p}^{\circ}=0.7-0.9$. The corresponding pore parameters including the specific surface area, pore diameter and pore volume of the support before and after immobilization are summarized in Table 1.
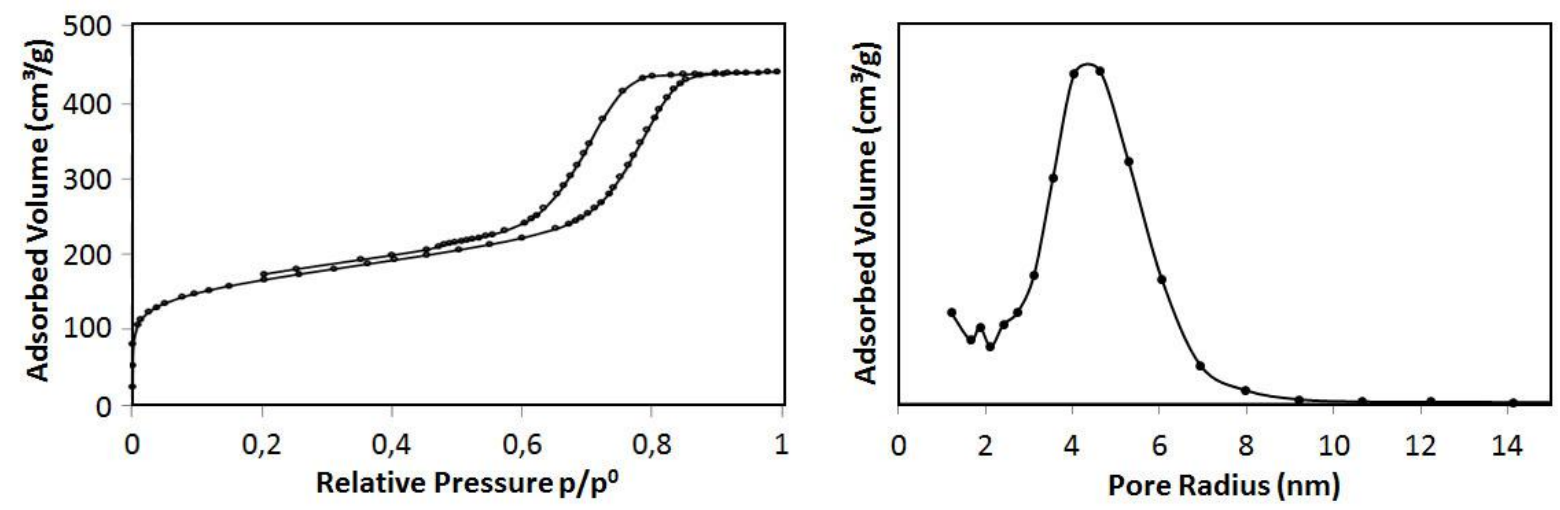

Figure 3 - Nitrogen sorption measurements and pore size distribution of mesoporous phenolic resin after covalent immobilization of the Jacobsen catalyst.

Table 1 - Textural parameters of the phenolic resin support before and after complex loading.

\begin{tabular}{cccc}
\hline & $\begin{array}{c}\mathbf{S}_{\mathbf{B E T}}{ }^{[\mathrm{a}]} \\
\left(\mathbf{m}^{2} / \mathbf{g}\right)\end{array}$ & $\begin{array}{c}\text { Pore size }^{[\mathbf{b}]} \\
(\mathbf{n m})\end{array}$ & $\begin{array}{c}\mathbf{V}_{\mathbf{p}}{ }^{[\mathbf{c}]} \\
\left(\mathbf{c m}^{3} / \mathbf{g}\right)\end{array}$ \\
\hline Original support & 604 & 9.2 & 0.68 \\
After immobilization & 397 & 8.1 & 0.52
\end{tabular}

[a] specific surface area calculated using the BET theory, [b] mean pore size determined by the BJH method, [c] total pore volume determined at $\mathrm{p} / \mathrm{p}^{\circ}=0.97-0.99$

After immobilization of the Mn-salen complex, the specific surface area, pore size and pore volume have decreased, also indicating a successful loading of the large complex inside the pores. It is suggested that the cylindrical open pores of the mesoporous phenolic resins are large enough to give easily access to both the bulky salen complexes (17 ̊ x $11 \AA$ ) and the substrates after anchoring.

In the entire anchoring strategy, it is important to prove unambiguously that the chlorine atom is substituted and an axial manganese-oxygen-support bond is formed, as shown in Figure 2. This is not an easy task. The phenolic resin is a dark brown/black substrate that makes a lot of spectroscopic characterization techniques unreliable or impossible. Moreover, the intense aromatic and aliphatic vibrations complicate the infrared and Raman characterization. In this respect, the distinction of the vibrations of the salen-complex anchored on the phenolic resin support was impossible, as these vibrations were largely overshadowed by the support (see figure SI.1) ${ }^{[35-}$ 37] 
Unfortunately, also XPS measurements have proven to be largely unreliable, probably due to a combination of the highly insulating character of the support, creating heavy surface charging and the fact that transition metals tend to reduce in high vacuum in the presence of carbon or phenolic resins ${ }^{[38]}$. In any case, our XPS measurements resulted in a irreproducible mix of several oxidation types of $\mathrm{Mn}$ on the surface, even when the same batch of samples was measured several times. Similar problems with XPS measurements on $\mathrm{VO}_{\mathrm{x}}$ loaded phenolic resins were observed by us previously ${ }^{[32]}$.

We have therefore synthesized a mesoporous phenolic resin that is completely free from Cl-ions, by using high purity $\mathrm{HNO}_{3}$ in the synthesis procedure, rather than the typical $\mathrm{HCl}$, to create the required acidity in the synthesis mixture. After grafting the Mn-salen complex, the heterogeneous catalyst was analyzed for its manganese and chlorine content with XRF. In case of physisorption, the complex would be present in the resin as a chloride salt, while in the case of covalent attachment, the manganese centers would bond with the phenolic oxygens, releasing the chlorine ions into solution. Quantitative XRF-measurements of this catalyst detected a chlorine content of only $0.005 \mathrm{mmol} / \mathrm{g}$, compared to a manganese loading of $0.09 \mathrm{mmol} / \mathrm{g}$. These results give a very good and direct proof of the covalent anchoring of the Jacobsen complex on our phenolic resin.

The Mn-content of $0.09 \mathrm{mmol} \mathrm{Mn} / \mathrm{g}$ measured with XRF corresponds to $\sim 0.1 \mathrm{Mn}$ complexes/nm². This suggests that the Mn-complexes are well dispersed on the surface of the mesoporous phenolic resin, which will avoid the formation of $\mu$-oxo-species through dimerization, and thus deactivation of the Jacobsen catalyst.

\subsection{Catalytic performance of the immobilized Jacobsen catalyst in the epoxidation of dialin}

The novel catalyst was evaluated for its catalytic performance in the epoxidation of dialin. As shown in Figure 4, the epoxidation of this conjugated olefin yields two enantiomers: 1,2-(R,S)-dihydronaphthalene oxide and 1,2$(\mathrm{S}, \mathrm{R})$-dihydronaphthtalene oxide.

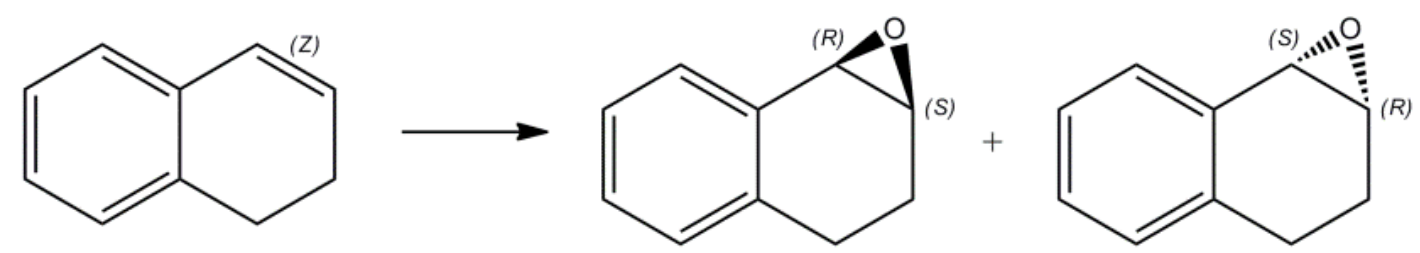

Figure 4 - Epoxidation of dialin (1,2-dihydronaphthalene) to 1,2-(R,S)-dihydronaphthalene oxide and 1,2(S,R)-dihydronaphthtalene oxide.

The heterogeneous catalyst was used in three consecutive epoxidation runs of 24 hours, and filtered off and washed with dichloromethane after each run. As a reference, the catalyst was compared to the Jacobsen catalyst in the homogeneous phase. The reaction mixtures were analyzed after 24 hours reaction at room temperature. Table 2 shows an overview of the catalytic performance of the different catalysts in the epoxidation of 1-2dialin. The homogeneous catalyst shows a high catalytic activity: after 24 hours of reaction, $90 \%$ of the substrate is converted and a TON of 34 is calculated. For the Jacobsen catalyst immobilized on the mesoporous phenolic resin, a conversion of $62 \%$ is obtained, corresponding to a TON of 10 . 
Table 2 - Overview of the catalytic performance of the homogeneous and the immobilized Mn-salen catalysts in the asymmetric epoxidation of dialin

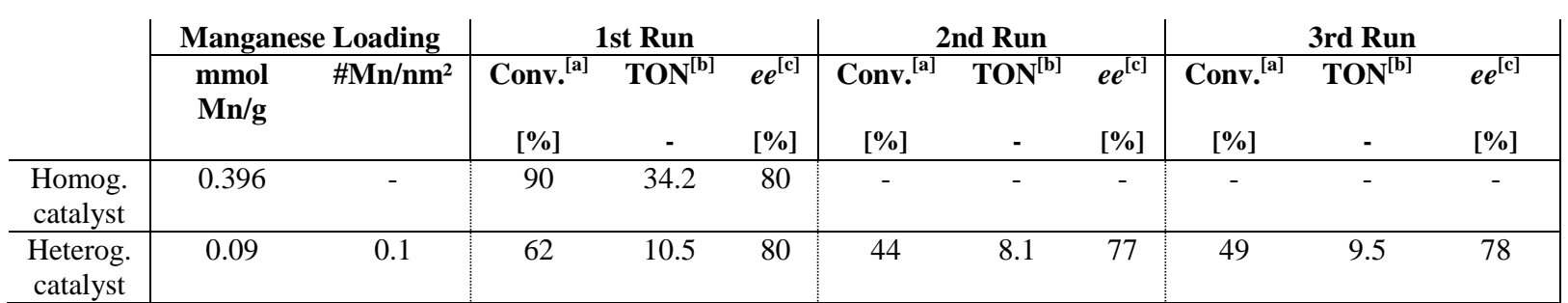

[a] Conversions determined by chiral HPLC after 24 hours, the masses of initial and recovered heterogeneous catalyst for each run are respectively $0.061,0.052$ and $0.048 \mathrm{~g}$. The amount of homogeneous catalyst was adjusted to have the same amount of Mn centers as used in the heterogeneous system (about $0.0045 \mathrm{mmol} \mathrm{Mn}$ ), [b] turn over number (TON) determined as number of dialin converted per number of manganese centers after 24 hours, [c] enantiomeric excess determined by chiral HPLC.

The enantioselectivity of the catalysts was measured by means of chiral HPLC. The $e e$ of the homogeneous Jacobsen catalyst was $80 \%$ (excess of 1,2-(S,R)-dihydronaphthalene oxide). The ee value of the Jacobsen catalyst immobilized on the mesoporous phenolic resin was $80 \%$ as well, which indicates that the immobilization of the complex did not alter the asymmetric induction character of the catalyst. In a second run the conversion of the immobilized catalyst decreased to $44 \%$, although the turn over number indicates that the catalyst maintained its conversion efficiency. The enantiomeric excess in this run was $77 \%$. In a third run the conversion was $49 \%$, with a TON of 9.5 and an $e e$ of $78 \%$. These results show that the Jacobsen catalyst on the mesoporous phenolic resin can be reused and perfectly maintains its high enantioselectivity in the asymmetric epoxidation of dialin. There is a small reduction in conversion, but only from the first to the second run, after which the activity of the catalyst no longer decreases.

To assess possible manganese leaching from the support, the reaction mixtures were analysed with XRF spectroscopy after each catalytic test. The manganese content of these filtrates was found to be below the detection limit of the XRF analyser (ppm range). Additionally, a split test was performed where the catalyst was filtrated from the reaction mixture after 5 hours of reaction. The reaction mixture was further analysed in time to verify if the conversion would increase. If catalytically active species (Jacobsen complex, Mn-species, radicals, ...) would have leached into the solution, the substrate conversion would continue in time. Figure 5, however, shows that the conversion remains constant once the catalyst is removed. The XRF analyses and the split test indicate that the heterogenous catalyst does not suffer from leaching. 


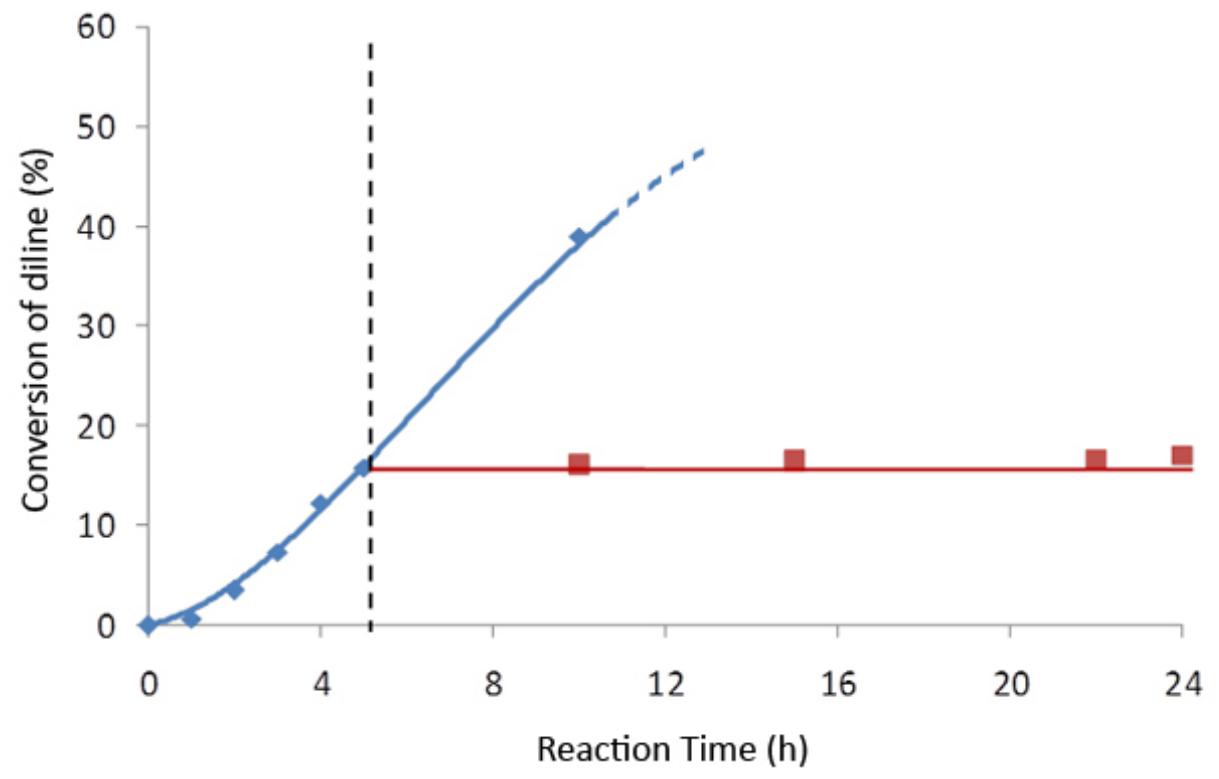

Figure 5 - Split test. After 5 hours of reaction the filtrate was analyzed (square symbols).

The observed stability of this newly developed manganese salen catalyst can be understood by the highly stable phenolic support-oxygen-metal bond, as our group reported earlier ${ }^{[39]}$. Contrary to silica supports, the covalent CO-Metal bond does not hydrolyse easily, yielding leach-proof catalysts.

\section{Conclusion}

In this contribution, mesoporous phenolic resins are presented as novel support for the covalent immobilization of the Jacobsen catalyst. The catalyst anchoring consists of a simple and direct reflux procedure resulting in a direct axial coordination of the complex on the surface phenol groups. A manganese loading of $0.09 \mathrm{mmol} / \mathrm{g}$ was obtained, corresponding to $0.1 \mathrm{Mn}$ complexes $/ \mathrm{nm}^{2}$. This loading suggests that the Mn-complexes are well dispersed on the surface of the mesoporous phenolic resin. The covalent bonding of the Mn center to the phenolic oxygen of the support has been proven by XRF of the immobilized Jacobsen catalyst on a chlorine-free mesoporous phenolic resin. The heterogeneous catalyst shows good catalytic activity in the asymmetric epoxidation of dialin, using sodium hypochlorite as oxidant. Conversions of $62 \%$ are obtained in the initial catalytic run where 1,2-(S,R)-dihydronaphthalene oxide is formed with an ee of $80 \%$. The results of a second and third catalytic run indicate that the heterogeneous system can be recovered with maintained converting efficiency and enantioselectivity $(\sim 78 \%)$. A split test and reaction filtrate analysis with XRF proved that the Jacobsen catalyst bound on the mesoporous resin is a real heterogeneous catalyst that does not suffer from leaching.

\section{Acknowledgments}

The authors acknowledge the Special Research Fund Grants Nr. 05V00812 (AUGent) and 01J00107 (UGent), the Ghent University BOF Grant Nr. 01P02911T and the European Research Council (FP7(2007-2013) ERC Grant Nr. 240483). José Martins is acknowledged for the NMR measurements. 


\section{References}

R. C. Ewins et al., Chemical Communications, 1967, 1085-1086.

J. G. Smith, Synthesis-Stuttgart, 1984, 629-656.

P. Besse et al., Tetrahedron, 1994, 50, 8885-8927.

M. Wu et al., Advanced Synthesis \& Catalysis, 2011, 353, 3014-3022.

K. Srinivasan et al., Journal of the American Chemical Society, 1986, 108, 2309-2320.

T. Katsuki, in Catalytic Asymmetric Synthesis, ed. I. Ojima, Wiley-VCH (US), 2000, pp. 287 - 326.

J. T. Groves et al., Journal of the American Chemical Society, 1983, 105, 6243-6248.

P. Pietikaïnen, PhD thesis, University of Helsinki (FL), 2001.

B. Cardoso et al., Microporous and Mesoporous Materials, 2005, 86, 295-302.

10. E. N. Jacobsen, Wu, M.H., in Comprehensive Asymmetric Catalysis, ed. E. N. Jacobsen, Pfaltz, A., Yamamoto, H., Springer, 1999, pp. 649 - 677.

11. T. Katsuki, Coordination Chemistry Reviews, 1995, 140, 189-214.

12. R. N. Ji et al., Journal of Inorganic and Organometallic Polymers and Materials, 2010, 20, 675-683.

13. I. Kuzniarska-Biernacka et al., Applied Clay Science, 2011, 53, 195-203.

14. I. Kuzniarska-Biernacka et al., Catalysis Letters, 2010, 134, 63-71.

15. L. L. Lou et al., Microporous and Mesoporous Materials, 2011, 142, 214-220.

16. T. Luts et al., Journal of Molecular Catalysis a-Chemical, 2007, 261, 16-23.

17. T. C. O. Mac Leod et al., Applied Catalysis a-General, 2010, 372, 191-198.

18. D. P. Serrano et al., Applied Catalysis a-General, 2008, 335, 172-179.

19. X. C. Zou et al., Acta Chimica Sinica, 2011, 69, 431-437.

20. D. E. De Vos et al., Chemical Reviews, 2002, 102, 3615-3640.

21. P. P. Knops-Gerrits et al., Journal of Molecular Catalysis a-Chemical, 1997, 117, 57-70.

22. P. P. Knops-Gerrits et al., Nature, 1994, 369, 543-546.

23. U. Diaz et al., Proceedings of the Royal Society a-Mathematical Physical and Engineering Sciences, 2012, 468, 1927-1954.

24. B. Clapham et al., Tetrahedron, 2001, 57, 4637-4662.

25. B. M. L. Dioos et al., Advanced Synthesis \& Catalysis, 2006, 348, 1413-1446.

26. N. E. Leadbeater et al., Chemical Reviews, 2002, 102, 3217-3273.

27. T. S. Reger et al., Journal of the American Chemical Society, 2000, 122, 6929-6934.

28. D. C. Sherrington, Catalysis Today, 2000, 57, 87-104.

29. A. R. Silva et al., Carbon, 2004, 42, 3027-3030.

30. P. Das et al., Catalysis Letters, 2009, 129, 367-375.

31. F. Maia et al., Journal of Molecular Catalysis a-Chemical, 2009, 305, 135-141.

32. I. Muylaert et al., Chemical Communications, 2008, 4475-4477.

33. I. Muylaert et al., Advances in Colloid and Interface Science, 2012, 175, 39-51.

34. J. M. Vega-Perez et al., Tetrahedron, 2011, 67, 7057-7065.

35. M. P. Feth et al., Chemistry-a European Journal, 2003, 9, 1348-1359.

36. T. Ben Zid et al., Reaction Kinetics Mechanisms and Catalysis, 2010, 100, 131-143.

37. J. Cubillos et al., Applied Catalysis a-General, 2009, 366, 348-352.

38. B. M. Weckhuysen et al., Catalysis Today, 2003, 78, 25-46.

39. I. Muylaert et al., European Journal of Inorganic Chemistry, 2012, 251-260. 